\title{
PREFERENSI HABITAT PERSARANGAN PENYU DI KAWASAN PULAU KECIL
}

(Preference for Nesting Habitat of Turtles in Island Areas)

\author{
ZETH PARINDING \\ Kepala Sub Bagian Program dan Kerjasama pada Balai Besar Taman Nasional Teluk \\ Cenderawasih \\ e-mail: zethparksdae@gmail.com
}

\begin{abstract}
ABSTRAK
Penyu melakukan persarangan di setiap kawasan pulau kecil pada Bentang Laut Kepala Burung Papua dipengaruhi preferensinya terhadap tekstur pasir dan jenis-jenis tanaman naungan dan perakarannya. Tujuan penelitian ini adalah mengidentifikasikan preferensi habitat persarangan bagi penyu baik tekstur pasir maupun jenis-jenis tumbuhan sekitar persarangan pada kawasan pulau kecil yakni Pulau Venu (SML, Kaimana) dan Pulau Wairundi (TNTC, Teluk Wondama). Metode penelitian menggunakan metode kuantitatif survey menggunakan Aplikasi SPSS versi 20 dengan uji Chi square. Substrat pasir, yang diambil pada kedalaman $50 \mathrm{~cm}$, dilakukan pengujian tekstur pasir menggunakan alat sieve shakers, untuk menentukan butiran pasir bertektur halus, pasir bertektur sedang, dan pasir bertektur kasar. Selanjutnya jenis-jenis tumbuhan naungan dan perakarannya diukur dari sarang terdekat. Preferensi habitat persarangan penyu pada kawasan pulau kecil di Bentang Laut Kepala Burung Papua ditemukan pada pasir bertekstur sedang, dan jenis-jenis tumbuhan adalah Tournefortia argentea dan Scaeveola taccada.
\end{abstract}

Kata Kunci: Preferensi Habitat Persarangan, Penyu, Kawasan Pulau Kecil

\begin{abstract}
Sea turtles nest in every small island area of the Papua Bird's Head Seascape influenced by their preference for sand texture and their types of shade and rooting plants. The purpose of this study was to identify the preferences of the sea turtle nesting habitat for sea turtles both sand texture and plant species around the nesting grounds in the small island area, i.e.: Venu Island (Marine Wildlife Santuary, Kaimana Regional), and Wairundi Island (National Park of Teluk Cenderawasih, Wondama Bay Regional). The research method uses Application of SPSS version 20 with Chi square test. Sand substrates, taken at a depth of 50cm, are performed sand texture testing using sieve shakers, to determine fine-textured sand, medium-textured sand, and coarsetextured sand. Furthermore, the types of shade plants and their rooting are measured from the nearest nests. The preferences of sea turtle nesting habitats on small island areas in the Papuan Bird's Head Seascapes are found medium-textured sand, and the plant species are Tournefortia argentea and Scaeveola taccada
\end{abstract}

Key Word: Preference for Nesting Habitat, Sea Turtles, Small Island Areas

\section{PENDAHULUAN}

Penyu diketahui sebagai jenis satwa migran yang memiliki wilayah jelajah yang cukup luas, yang mana keberadaan populasi dan habitatnya sangat dipengaruhui berbagai faktor, yakni ekologi, ekonomi, sosial, budaya, kelembagaan pengelolaannya, dan juga ketahanan spesies dalam hal fekunditas dan lingkungannya (Parinding, 2016), dan juga lebar pantai berpasir (Dima et.al. 2020, Haumahu et.al. 2017, Juliono \& Ridhwan 2017, Nuitja 1999; Parinding 2010, Parinding 2011, Parinding et.al. 2015, Parinding et.al. 2016, Pranata et.al. 2020, Sineri et.al. 2020, Tasha et.al. 2018). FAO 2015, dan Ario et.al. 2016 menyebutkan ada 7 jenis penyu di Dunia. di Indonesia ditemukan sebanyak 6 jenis. Adapun jenis-jenis penyu yang pernah ditemukan pada bentang laut 
kepala burung sebanyak 4 jenis, yaitu: jenis penyu hijau (Chelonia mydas), penyu sisik (Eretmochelys imbricata), penyu lekang (Lepidochelys olivicea), dan penyu belimbing (Dermochelys coriacea). Sedangkan 2 jenis penyu lainnya yang pernah ditemukan di Indonesia, yaitu: penyu pipih (Natator depressus), dan penyu tempayan (Caretta caretta). Ke-6 jenis penyu ini dalam melakukan persarangannya diletakkan pada media pasir dengan kedalaman tertentu dan pada naungan habitat tertentu.

Preferensi habitat penyu sangat mempengaruhi dalam persarangannya, pada kawasan pantai berpasir, dan juga vegetasi naungan dan perakarannya baik di pulau besar maupun di pulau kecil. Hal ini menjadi pilihan penyu dalam meningkatkan populasinya, ketersedian makanan, perairan tempat kawin di sekitar pulau dan pesisir pantai yang berpasir, dan juga perlindungan terhadap predator alami maupun manusia. Penyu melakukan persarangan, pada umumnya ditemukan pada pasir berstektur halus sampai sedang dengan komposisi pasir lebih dari $85 \%$ (Haumahu et.al. 2017, Ismane et.al. 2018, Nuitja 1992, Parinding 2016a, \& Parinding 2016b), sedangkan persarangan diletakkan dekat vegetasi sebagai bagian kelembaban dan suhu bagi kebutuhan persarangannya, yang berfungsi sebagai naungan dan perakarannya untuk kekokohan persarangannya. Kawasan pulau kecil memiliki jenis vegetasi tertentu yang sering digunakan penyu melakukan persarangannya, dan juga pada pasir yang bertekstur halus sampai sedang. Berkaitan dengan tekstur pasir dan vegetasi yang disukai penyu dalam melakukan persarangan pada kawasan pulau kecil. Dengan demikian penulisan ini, untuk menggambarkan pengelolaan yang dibutuhkan sesuai tekstur pasir dan vegetasi yang perlu dipertahankan.

Penelitian ini dilakukan pada kedua kawasan pulau kecil yang berada pada Bentang Laut Kepala Burung-BLKB (Seascape Head Birds-BHS) Papua di Provinsi Papua Barat, yakni: pulau Venu pada Suaka Margasatwa di Kabupaten Kaimana, dan pulau Wairundi pada Taman Nasional Teluk Cenderawasih di Kabupaten Teluk Wondama Adapun tujuan penulisan ini adalah untuk menemukan tekstur pasir ideal dan vegetasi yang disukai penyu dalam melakukan persarangannya pada kawasan pulau kecil.

\section{METODE PENELITIAN}

Pengamatan di lakukan pada Pulau Venu di Kabupaten Kaimana Papua Barat dan pada Pulau Wairundi diKabupaten Teluk Wondama, Papua Barat. Kedua tempat ini berada pada Bentang Laut Kepala Burung-BLKB (Seascape Head Birds-BHS) Papua di Provinsi Papua Barat, yakni: pulau Venu pada Suaka Margasatwa di Kabupaten Kaimana, dan pulau Wairundi pada Taman Nasional Teluk Cenderawasih di Kabupaten Teluk Wondama.

\section{Alat dan Bahan Penelitian}

Dalam melakukan penelitian memerlukan alat-alat dan bahan penelitian. Alat-alat penelitian yang digunakan, antara lain: speedboat, peta lokasi penelitian, buku identifikasi penyu (Ballamu \& Verdiel, 2010), meteran pita 50m, sieve shakers (Valera-Avecedo et.al. 2009), polyethilen, kamera, tropper, head splashligt, personal use, senter besar, perangkat computer, dan software SPSS versi 26 dengan menggunakan uji Chi Square. Sedangkan bahan penelitian berupa alkohol dan kertas koran.

\section{Teknik Pengambilan Data}

Berdasarkan data awal dan time seri dari keberadaan persarangan penyu, data diambil hanya pada bulan April mewakili bulan musim hujan dan bulan Oktober mewakili bulan musim kemarau. Hal ini dilakukan sebagai perwakilan data, yang mana paling banyak ditemukan penyu melakukan persarangan. Selain itu, bekas persarangan penyu di sekitar tumbuhan yang pernah diidentifikasi. 
Setiap penjuru mata angin ditempatkan pos/stasiun pengamatan, Selanjutnya melakukan pengamatan setiap tempat yang menjadi tempat persarangan dari penyu di bagian pantai berpasir, yang terdapat vegetasi maupun tanpa vegetasi. Pada setiap kumpulan persarangannya tersebut berjarak 1 meter atau terdekat dari sarang tersebut, diambil pasirnya dengan kedalamaan $50 \mathrm{~cm}$ sebagai keterwakilan dari penjuru mata angin, untuk menentukan tekstur pasirnya. Selain itu setiap jenis vegetasi dicatat, yang mana ada persarangannya baik yang berada berdekatan maupun berada di bawah vegetasinya. Selanjutnya pasir dari setiap pos/stasiun pengamatan seberat 500 gram yang diambil tersebut di taruh ke dalam plastik, untuk dikirim ke pusat laboratorium tanah di Bogor dalam pengujian tekstur pasirnya. Pasir bertekstur halus (diameter pasir berukuran $\leq 0,25 \mathrm{~mm}$ ), pasir bertekstur sedang (diameter pasir berukuran 0,50-0,25mm), dan pasir bertekstur kasar (diameter pasir berukuran $\geq 0,50 \mathrm{~mm}$ ), pasir bertekstur sedang (diameter pasir berukuran 0,50$0,25 \mathrm{~mm}$ ). Sedangkan jenis-jenis vegetasi yang menjadi naungan atau berdekatan dengan persarangan penyu diidentifikasi.

Hasil survei awal menunjukkan tempat persarangan penyu yang sering digunakan pada lokasi pulau Venu, Kabupaten Kaimana sebanyak 40 plot pengamatan. Sedangkan tempat persarangan penyu yang sering digunakan pada lokasi pulau Wairundi, Kabupaten Teluk Wondama sebanyak 20 plot pengamatan.

\section{Metode pengujian}

Metode penelitian menggunakan Aplikasi SPSS versi 20 dengan uji Chi square. Preferensi habitat persarangan dilakukan pada substrat pasir sebagai pengukuran nominal,sedangkan jenisjenis tumbuhan sebagai pengukuran ordinalnya. Pengujian ini dilakukan pada kawasan pulau kecil di Bentang Laut Kepala Burung Papua, Provinsi Papua Barat baik di Pulau Venu, Kabupaten Kaimana maupun di Pulau Wairundi, Kabupaten Teluk Wondama.

\section{HASIL DAN PEMBAHASAN}

Kegiatan yang dilakukan pada Pulau Venu di Kabupaten Kaimana Papua Barat dan pada Pulau Wairundi di Kabupaten Teluk Wondama, Papua Barat menunjukkan bahwa pulaunya didominasi pasir $\geq 95 \%$. Berdasarkan hasil laboratorium tanah di Bogor menunjukkan substrat pasir tempat penyu melakukan persarangan bertekstur sedang (diameter pasir berukuran 0,50$0,25 \mathrm{~mm}$ ) yakni ukuran rata-rata $\geq 40.30 \mathrm{~mm}$. Sedangkan Berkaitan dengan jenis-jenis vegetasi yang ditemukan ada persarangan penyu, yaitu: Cemara laut/ekor kuda (Casuarina equisetifolia), Babakoan (Tournefortia argenta), Merambong (Scaeveola taccada), Waru (Hibiscus tiliances), Seruni (Widelia biflora), dan katang-katangan (Ipomea pescaprea). Walaupun ditemukan Cemara ekor kuda (Casuarina equisetifolia) lebih mendominasi pada kawasan pulau kecil dan juga jenis Seruni (Widelia biflora), dan katang-katangan (Ipomea pescaprea).

Pengujian menggunakan aplikasi uji Chi Square terhadap substrat berpasir dengan jenisjenis tumbuhan naungan terdekat dengan persarangan penyu pada kedua lokasi yang berbeda. Pengujian preferensi persarangan penyu terhadap tekstur pasir dan jenis-jenis tumbuhannya ditemukan pada pasir bertekstur sedang dan jenis-jenis tumbuhan, yakni: Tournefortia argentea dan Scaeveola taccada. Hasil kedua lokasi penelitian tersebut menunjukkan hasil yang sama. Adapun hasil pengujian preferensi habitat persarangan penyu pada Pulau Venu disajikan pada Tabel 1, Sedangkan hasil pengujian dan habitat persarangan penyu pada Pulau Wairundi disajikan pada Tabel 2. 
Vol 1. No. 2 Tahun 2021

Tabel 1. Preferensi habitat persarangan penyu pada Pulau Venu, Kabupaten Kaimana

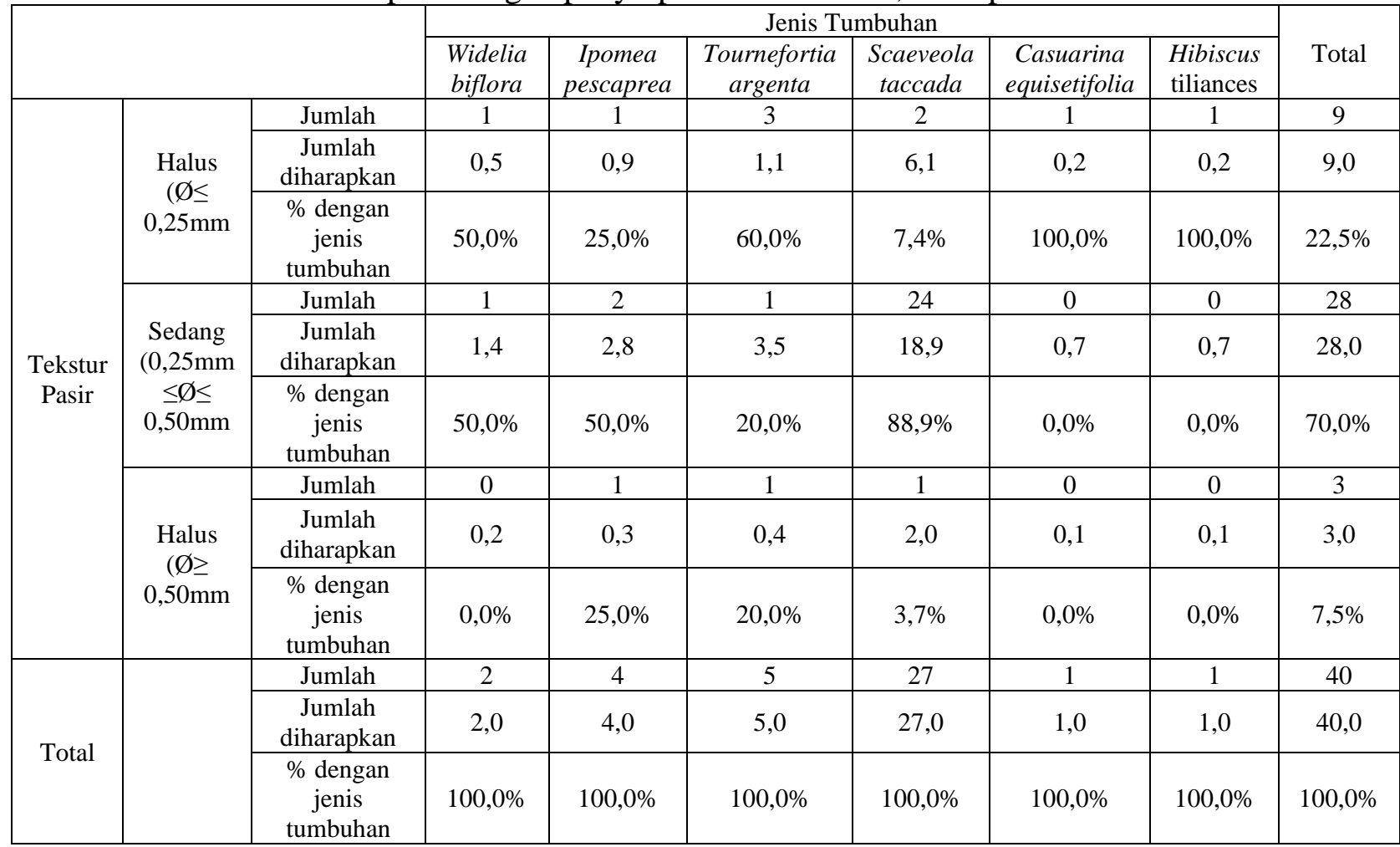

Catatan: Pengujian Pearson Chi-Square menunjukkan nilai 25.273 dengan df 10, sedangkan koefisien kontingensi adalah 0.622 .

Tabel 2. Preferensi habitat persarangan penyu pada Pulau Wairundi, Kabupaten Teluk Wondama

\begin{tabular}{|c|c|c|c|c|c|c|c|c|c|}
\hline & \multicolumn{6}{|c|}{ Jenis Tumbuhan } & \multirow[b]{2}{*}{ Total } \\
\hline & & & $\begin{array}{l}\text { Widelia } \\
\text { biflora }\end{array}$ & $\begin{array}{c}\text { Ipomea } \\
\text { pescaprea }\end{array}$ & $\begin{array}{c}\text { Tournefortia } \\
\text { argenta }\end{array}$ & $\begin{array}{c}\text { Scaeveola } \\
\text { taccada }\end{array}$ & $\begin{array}{c}\text { Casuarina } \\
\text { equisetifolia }\end{array}$ & $\begin{array}{l}\text { Hibiscus } \\
\text { tiliances }\end{array}$ & \\
\hline \multirow{9}{*}{$\begin{array}{l}\text { Tekstur } \\
\text { Pasir }\end{array}$} & \multirow{3}{*}{$\begin{array}{l}\text { Halus } \\
\qquad(\varnothing \leq \\
0,25 \mathrm{~mm}\end{array}$} & Jumlah & 0 & 1 & 1 & 1 & 2 & 0 & 5 \\
\hline & & $\begin{array}{c}\text { Jumlah } \\
\text { diharapkan }\end{array}$ & 0,8 & 1,0 & 0,5 & 2,0 & 0,5 & 0,3 & 5,0 \\
\hline & & $\begin{array}{l}\% \text { dengan } \\
\text { jenis } \\
\text { tumbuhan }\end{array}$ & $0,0 \%$ & $25,0 \%$ & $50,0 \%$ & $12,5 \%$ & $100,0 \%$ & $0,0 \%$ & $25,0 \%$ \\
\hline & \multirow{3}{*}{$\begin{array}{c}\text { Sedang } \\
(0,25 \mathrm{~mm} \\
\leq \emptyset \leq \\
0,50 \mathrm{~mm}\end{array}$} & Jumlah & 3 & 1 & 1 & 7 & 0 & 1 & 13 \\
\hline & & $\begin{array}{c}\text { Jumlah } \\
\text { diharapkan }\end{array}$ & 2,0 & 2,6 & 1,3 & 5,2 & 1,3 & 0,7 & 13,0 \\
\hline & & $\begin{array}{l}\% \text { dengan } \\
\text { jenis } \\
\text { tumbuhan }\end{array}$ & $100,0 \%$ & $25,0 \%$ & $50,0 \%$ & $87,5 \%$ & $0,0 \%$ & $100,0 \%$ & $65,0 \%$ \\
\hline & \multirow{3}{*}{$\begin{array}{l}\text { Halus } \\
\qquad \varnothing \geq \\
0,50 \mathrm{~mm}\end{array}$} & Jumlah & 0 & 2 & 0 & 0 & 0 & 0 & 2 \\
\hline & & $\begin{array}{c}\text { Jumlah } \\
\text { diharapkan }\end{array}$ & 0,3 & 0,4 & 0,2 & 0,8 & 0,2 & 0,1 & 2,0 \\
\hline & & $\begin{array}{l}\% \text { dengan } \\
\text { jenis } \\
\text { tumbuhan }\end{array}$ & $0,0 \%$ & $50,0 \%$ & $0,0 \%$ & $0,0 \%$ & $0,0 \%$ & $0,0 \%$ & $10,0 \%$ \\
\hline \multirow{3}{*}{ Total } & & Jumlah & 3 & 4 & 2 & 8 & 2 & 1 & 20 \\
\hline & & $\begin{array}{c}\text { Jumlah } \\
\text { diharapkan }\end{array}$ & 3,0 & 4,0 & 2,0 & 8,0 & 2,0 & 1,0 & 20,0 \\
\hline & & $\begin{array}{l}\% \text { dengan } \\
\text { jenis } \\
\text { tumbuhan }\end{array}$ & $100,0 \%$ & $100,0 \%$ & $100,0 \%$ & $100,0 \%$ & $100,0 \%$ & $100,0 \%$ & $100,0 \%$ \\
\hline
\end{tabular}

Catatan: Pengujian Pearson Chi-Square menunjukkan nilai 18.231 dengan df 10, sedangkan koefisien kontingensi adalah 0.691 . 
Pasir yang ditemukan pada Pulau Venu dan Pulau Wairundi sebagai tempat persarangan penyu karena hampir 99\%, yang mana di dominasi pasir halus (kuarsa) sampai dengan pasir kasar (koral). Keberhasilan persarangan yang dilakukan penyu dipengaruhi kestabilan suhu pasir persaranganyang juga dipengaruhi perakaran dari vegetasi yang ada dan juga pasir bertekstur sedang sampai dengan halus (Parinding, 2015, 2016a, 2016b, Rofiah et.al. 2012). Tekstur pasir sedang ini dapat memberikan keberhasilan penetasan telur penyu lebih dari $85 \%-95 \%$ untuk menjadi tukik (anak penyu). Tekstur pasir sangat mempengaruhi kestabilan suhu pasir pada kedalaman pada $50 \mathrm{~cm}$.

Berdasarkan hal tersebut di atas, yang mana dapat menjadi indikator dari persentase jenis kelamin baik betina maupun jantan dari tukik yang dihasilkan dari dalam persarangan tersebut. Suhu inkubasi pada keberhasilan penetasan telur penyu berkisar antara $24-33^{\circ} \mathrm{C}$. Kisaran suhu ini memberikan toleransi bagi perkembangan embrio dari telur penyu tidak terganggu dalam proses penetasan menjadi tukik. Selain itu kisaran suhu ini dapat menghasilkan daya tetas terbaik dan juga relatif singkat proses inkubasinya. Biasanya keberhasilan peneluran telur menjadi tukik lebih dari $85 \%$.

Kestabilan suhu dan kelembaban pasir persarangan bagi penyu juga dipengaruhi perakaran cemara ekor kuda/laut, yang mendominasi di kawasan pulau kecil. Namun preferensi persarangan penyu terhadap jenis vegetasi ditemukan pada jenis Babakoan (Tournefortia argenta), Merambong (Scaeveola taccada). Kedua jenis ini ternyata berdekatan dengan dengan jenis Cemara ekor kuda (Casuarina equisetifolia), yang berada di belakang kedua jenis yang paling disukai penyu dalam melakukan persarangannya. Di sisi lain ada 2 jenis tumbuhan rambatan seperti: Seruni (Widelia biflora), dan katang-katangan (Ipomea pescaprea), yang mana mampu memberikan kestabilan suhu dan juga melindungi lokasi peneluran dari rayap penggangu di sekitar pasir penyu melakukan persarangannya. Jenis tumbuhan Seruni (Widelia biflora) mampu menghambat perkembangan jenis-jenis rayap pada jenis kayu baik batang maupun perakarannya (Ulvia, 2017). Kayu tersebut dapat berasal dari pohon kayu yang tumbang dan juga potongan kayu, yang terhempas di sekitar vegetasi pantai pada pantai peneluran penyu. Dengan demikian daerah sekitar persarangan, yang mana kayunya dapat lapuk cepat yang berfungsi sebagai naungan untuk memberikan kestabilan suhu pasir dapat dihambat pelapukannya. Di satu sisi, keberadaan tumbuhan seruni, membantu menghindarkan pemangsaan cadangan makanan yang dimiliki tukik dari predator alaminya, serangga atau semut atau rayap dalam proses penyu keluar dari sarang, sebelum menuju ke laut lepas dalam menghadapi predator baik alami maupun manusia. Tumbuhan seruni di sekitar tumbuhan Babakoan (Tournefortia argenta), Merambong (Scaeveola taccada) mampu memberikan perlindungan bagi penyu bersarang di bawah naungan ke dua jenis tumbuhan ini. Selain itu jenis perakaran dari ke 2 jenis tumbuhan ini memberikan porositas pasir, yang mana membantu kehidupan bagi makhluk di dalam pasir dan kekokohan pasir dalam memberikan kestabilan suhu dan lama kelembabannya.

Parinding (2015, 2016a, 2016b), Nugroho \& Sumardi (2010), \& Harjadi et.al. (2014) menyebutkan perakaran tumbuhan dan ketinggian vegetasi dapat memberikan kestabilan suhu pasir yang dibutuhkan penetasan telur penyu sesuai jenis-jenis penyunya. Perakaran dan ketinggian vegetasi mampu memberikan naungan sebagai bayangan, memperlambat rambatan dari matahari yabg jatuh ke permukaan lantai hutan yang berpasir, tekstur sedimen, angin, air hujan, termasuk aktivitas biologi di dalam sarang dan perubahan lingkungan di sekitarnya. Selanjutnya persarangan dekat dengan vegetasi dan perakarannya, untuk meningkatkan kelembaban dalam memberikan kestabilan suhu dari pasir tempat penyu melakukan persarangannya.

Dalam pengelolaan persarangan penyu di kawasan pulau kecil perlu memperhatikan salah satunya faktor ekologi.Dengan demikian pengelolaannya perlu memperhatikan pola kelimpahan dari reproduksi spesies penyunya, berkaitan dengan jumlah individu yang dihasilkan dan perbandingan jenis kelaminnya (Parinding, 2016a, 2016b). Kawasan pulau kecil, yang mana 
ditemukan penyu melakukan persarangan lebih di dominasi tumbuhan cemara ekor kuda/laut dalam membentuk stratum hutan di dalam pulau tersebut dan juga struktur daun jarum mampu mempertahankan keberadaan pulaunya dari abrasi pantai. Selain itu lebar pantai berpasir lebih luas dengan jenis tumbuhan Babakoan (Tournefortia argenta), Merambong (Scaeveola taccada) dan juga jenis tumbuhan merambat lainnya seperti: Seruni (Widelia biflora), dan katang-katangan (Ipomea pescaprea).

Banyak faktor yang mempengaruhi penyu melakukan persarangannya di antaranya berbagai pantai berpasir dengan tekstur pasir halus sampai sedang, dan jenis-jenis tanaman naungan dan perakarannya. Hal ini mampu memberikan sirkulasi udara yang baik dan juga kekokohan persarangannya baik saat peletakan telur maupun proses pengeraman telur didalam pasir. Selain itu, pemilihan tektur pasir dan naungan tumbuhan dan perakarannya mampu memberikan kestabilan suhu dan juga memudahkan tukik keluar dari dalam persarangannya. Kestabilan suhu sangat mempengaruhi pembentukan jenis kelamin selama proses persarangan disebabkan perbedaan suhu di dalamnya.

Dengan demikian, strategis pengelolaan persarangan penyu di pulau memerlukan perbanyakan jenis-jenis dari tumbuhan Babakoan (Tournefortia argenta), Merambong (Scaeveola taccada). Setelah melakukan pemindahan telur penyu pada daerah yang dilakukan penanaman tumbuhan ini, keberhasilan penetasan telur menjadi tukik berkisar antara 90-96\%. Selain itu, tumbuhan Cemara ekor kuda (Casuarina equisetifolia) perlu dilakukan peremajaan, dan juga jenis tumbuhan waru (Hibiscus tiliaceus). Jenis tumbuhan waru (Hibiscus tiliaceus), yang mana keberdaaannya telah banyak tumbang disebabkan abrasi pantai. Jenis tumbuhan ini dengan musim bunganya, biasanya dapat mendatangkan jenis-jenis penyu tertentu naik ke pantai untuk melakukan persarangan. Sedikit banyak jenis tumbuhan ini telah hilang dari beberapa pulau tempat penyu melakukan persarangan.

\section{KESIMPULAN}

Banyak faktor yang mempengaruhi penyu melakukan persarangannya di antaranya berbagai pantai berpasir dengan tekstur pasir halus sampai sedang, dan jenis-jenis tanaman naungan dan perakarannya. Hal ini mampu memberikan sirkulasi udara yang baik dan juga kekokohan persarangannya baik saat peletakan telur maupun proses pengeraman telur didalam pasir. Selain itu, pemilihan tektur pasir dan naungan tumbuhan dan perakarannya mampu memberikan kestabilan suhu dan juga memudahkan tukik keluar dari dalam persarangannya. Kestabilan suhu sangat mempengaruhi pembentukan jenis kelamin selama proses persarangan disebabkan perbedaan suhu di dalamnya.

Preferensi habitat persarangan penyu ditemukan baik pada tekstur pasir maupun pada jenisjenis tumbuhan sekitar persarangan pada kawasan pulau kecil. Preferensi habitat persarangan penyu pada kawasan pulau kecil di Bentang Laut Kepala Burung Papua ditemukan pada pasir bertekstur sedang dan pada jenis-jenis tumbuhan, yakni: Tournefortia argentea dan Scaeveola taccada

\section{DAFTAR PUSTAKA}

Ario R, Wibowo E, Pratikto I, \& Fajar S. 2016. Pelestarian habitat penyu dari ancaman kepunahan di Turtle Conservation and Education Center (TCEC), Bali. Jurnal Kelautan Tropis 19 (1), 6066, from https://doi.org/10.14710/jkt.v19i1.602

Ballamu, \& Ferdiel. 2010. Prosedur Monitoring di Pantai Peneluran. (1 ed). Papua Barat, Sorong: Yayasan Penyu Papua (YPP).

Dima AOM, Klaas ZC, Meye ED, Kla DF, Ati VM, \& Momo AN. 2020. Karakteristik fisik pantai dan distribusi sarang alami penyu lekang (Lepidochelys olivacea) dinpantai Sosadale RoteNdao Nusa Tenggara Timur. biofaal Journal 1 (2), 55-65. 
Food and Agriculture Organization (FAO). (2005). Sea Turtles Conservation and Fisheries. Rome, Italy: FAO, Fisheries and Aquaculture Departement.

Hanafiah. (2012). Dasar-dasar Ilmu Tanah. (6 ed.). Jakarta: Rajawali Pers

Haumahu JP, Maail R, Fransz JJ, Rehatta H, \& Titarsole J. (2012). Memuliakan Laut: Buah Pikiran Akademisi Universitas Pattimura. (1 ed.). Ambon: Pattimura University Pers

Ismane MA, Kusmana C, Gunawan A, Affandi R, \& Suwardi S. (2018). Keberlanjutan pengelolaan kawasan konservasi penyu di Pantai Pangumbahan, Sukabumi, Jawa Barat. Jurnal Pengelolaan Sumberdaya Alam dan Lingkungan 8 (1), 36-43

Juliono, \& Ridhwan M. (2017). Penyu dan Usaha Pelestariannya. Serambi Saintia. V (1). ISSN: 2337-9952.

Ulvia N (2017). Pengaruh Ekstrak Daun Seruni (Wedelia biflora Linn) Terhadap Mortalitas Rayap Tanah (Coptotermes curvignathus Holmgren) sebagai Referensi Praktikum Mata Kuliah Entomologi. (Skripsi). Banda Aceh: Fakultas Tarbiyah dan Keguruan, Universitas Islam Negeri Ar-Raniry.

Nuitja IN. (1992). Biologi dan Ekologi Pelestarian Penyu Laut. Bogor. IPB Press.

Parinding Z. (2010). Buletin: Suaka Margasatwa Laut (SML) Pulau Venu. Papua Barat, Manokwari:.BBKSDAPB

Parinding Z. (2011). Buletin: Monitoring, pendataan, dan pembuatan sarana pembesaran tukik Kerjasama CI Program Kaimana, Seksi KSDA IV Kaimana, dan Masyarakat Adat. Papua Barat, Manokwari: BBKSDAPB.

Parinding Z, Basuni S, Purnomo H, Kosmaryandi N, \& Wardiatno Y. (2015). Karakteristik fisik peneluran Chelonia mydas, Linn. 1758 di Kaimana-Papua Barat. Jurnal Ilmu Pertanian Indonesia 20 (1), 26-32

Parinding Z, Basuni S, Purnomo H, Kosmaryandi N, \& Wardiatno Y. (2016a). The habitat characteristics of the Chelonia mydas nesting in Kaimana, West Papua. International Journal of Sciences: Basic and Applied Research (IJSBAR) 25(1), 266-277.

Parinding Z (2016b). Pembangunan Model Pengelolaan Adaptif Konservasi Penyu di Suaka Margasatwa Pulau Venu, Kaimana, Papua Barat. (Disertasi). Bogor: Sekolah Pascasarjana IPB

Pranata IPAW, Yulianda F, \& Kusrini MD. (2020). Pengaruh morfologi pantai terhadap preferensi bersarang penyu sisik (Eretmochelys imbricata, Linneaus 1766) di Pulau Belanda dan Kayu Angin Biru. Habitus Aquatica. 1 (1): 38-43, from http://journal.ipb.ac.id/index.php/ habitusaquatica/

Rofiah, Amalia, Hartati R, \& Wibowo E. (2012). Pengaruh naungan sarang terhadap presentase penetasan telur penyu lekang (Lepidochelys olivacea) di Pantai Samas Bantul. Jounal of Marine Research 1 (2), 103-108. Yogyakarta, from http://ejournals1.undip.ac.id/index.php/jmr

Sineri FK, Sianturi FG, Purmadewi GC, Mulyadi, Asyerem OM, Ogistira Ran, \& Charles T. (2020). Laporan: Monitoring populasi penyu di site pengamatan spesies prioritas Wairundi. Papua Barat, Manokwari.

Tasha L, Santosa A, \& Ario R. (2018). Studi Habitat Peneluran Penyu Sisik (Eretmochelys imbricata) di Pulau Menjangan Kecil Kepulauan Karimunjawa Kabupaten Jepara Jawa Tengah. Jurnal of MarineResearch. 7, 219-222, from https//ejournal.undip.ac.id/index.php. jmr.

Varela-Acevedo E, Eckert KL, Cambers G, \& Horrocks JA. (2009). Sea Turtle Nesting Beach Characterization Manual: Examining the Effects of Changing Coastline Processes on Hawksbill Sea Turtle (Eretmochelys imbicata) Nesting Habitat. USA, Beaufort, North Carolina: Duke University, Master's Project, 46-97. 